\title{
Evaluation of the disciplinary competences of the students of the Bachelor's degree in Nursing at 'Sapienza' University of Rome through the TECO: a cross-sectional study
}

\author{
Julita Sansoni*, Ilaria Farina and \\ Albina Paterniani \\ Department of Public Health, \\ 'Sapienza' University of Rome, \\ Rome, Italy \\ Email: julita.sansoni@uniroma1.it \\ Email: ilaria.farina@uniroma1.it \\ Email: albina.paterniani@uniroma1.it \\ *Corresponding author

\section{Marco Tofani}

'Sapienza' University of Rome,

Rome, Italy

Email: marco.tofani@uniroma1.it

\section{Giovanni Galeoto}

Department of Public Health,

'Sapienza' University of Rome,

Rome, Italy

Email: giovanni.galeoto@uniroma1.it

\begin{abstract}
The objective of the study is to evaluate whether the TECO-D is a useful tool for measuring the skills acquired by students during three years of the nursing bachelor's degree course at the 'Sapienza' University of Rome. The sample was recruited between January and April 2018. To be included in the study, the participants had to be enrolled in the bachelor's degree course in nursing at the 'Sapienza' University of Rome and had to be on track with the course's prescribed completion timeframe. The distribution of the scores for the TECO-D shows an increasing average (standard deviation) from $177.3 \pm 28$ in the first year up to $214.1 \pm 18.5$ for graduating students. Progress testing is a form of assessment in which groups of learners of different seniority (i.e., different classes in a curriculum) are given the same written test. The test is comprehensive by sampling all relevant disciplines in a curriculum, usually determined by a fixed blueprint. The evaluation of the single macro areas showed statistically significant data reflecting increasing knowledge regarding the progression of the skills received during the university course. Because of this, we can say that the TECO-D is a great tool for determining student's knowledge in order to evaluate study programs.
\end{abstract}

Comment [W1]: Author: Please confirm if J. Sansoni is the corresponding author.

Comment [W2]: Author: Please provide ful institutional address.

Comment [W3]: Author: Please reduce abstract (should be up to 150 words only). 
Keywords: TECO-D; progress test; nursing.

Reference to this paper should be made as follows: Sansoni, J., Farina, I., Paterniani, A., Tofani, M. and Galeoto, G. (xxxx) 'Evaluation of the disciplinary competences of the students of the Bachelor's degree in Nursing at 'Sapienza' University of Rome through the TECO: a cross-sectional study', Int. J. Innovation and Learning, Vol. X, No. Y, pp.000-000.

\section{Biographical notes:}

Comment [W4]: Author: Please provide the 100 words for each author).

This paper is a revised and expanded version of a paper entitled [title] presented at [name, location and date of conference].

Comment [W5]: Author: If a previous version of your paper has originally been presented at a conference please complete the statement to this effect or delete if not applicable. 


\section{Introduction}

Understanding and approaching learning differently is essential for dealing with theoretical and practical issues (Shandana et al., 2015). The improvement linked to learning is essential above all in the university environment; so as to prepare future professionals to exercise best practices in organisations. The scientific interest in teaching has developed a different learning process that aims to stimulate the critical thinking of students (Momi and Laxmi, 2014). This process uses tools such as the Progress Test to evaluate the student's learning and consequently the quality of the teaching. The Progress Test is, in university medical courses, the most common methodology for verifying students' knowledge (Mangayarkarasi et al., 2019). The most common way of verifying student knowledge is to use tests with different types of questions. First, there are questions that require students to remember and understand basic knowledge. We will refer to these as "simple questions". Second, there are questions that require students to apply, analyse and evaluate existing knowledge in combination with new information, which is provided through a case (Crowe et al., 2008).

Progress tests (PTs) in medical programmes are designed to assess applied medical knowledge at the level of a new graduate and are administered to all students across all years of a programme (Freeman et al., 2010; Schurwirth et al., 2010). PTs are intended to discourage students from preparing specifically for a test and then 'discarding' that knowledge. Applied medical knowledge from any stage of the curriculum can appear in a PT; therefore PTs should promote meaning-orientated learning and also foster long-term knowledge retention, while reducing superficial learning strategies such as rote learning and 'cramming and dumping (van der Vleuten et al., 1996; Crowe et al., 2008; Freeman et al., 2010; Schurwirth et al., 2010, van der Vleuten et al., 1996; Blake et al., 1996; Coombes et al., 2010).

In 2012, the Italian National Agency for the Evaluation of Universities and Research Institutes (ANVUR) started a project evaluating the learning outcomes of the Italian undergraduates through a test (Test on skills, TECO), holding that analysing skill levels is an important tool for monitoring the quality of the educational process (Blake et al., 1996).

European Union recommendations have been particularly interested in integrating citizenship and lifelong learning skills in national policies for the educational field, while the actions of institutions in the European Higher Education Area (EHEA) are progressively moving towards didactics centred on the student and on competences (European Standards and Guidelines for Quality Assurance (ESG), 2015).

In line with the ESG, Ministerial Decree number 987/2016 clarifies that TECO results, once fully operational, will become part of the system of indicators for evaluating teaching (self-assessment, periodic evaluation, accreditation - AVA). It is further clarified that collecting new data related to the Transversal and/or Disciplinary skills acquired by students will allow the development of indicators that will be used for periodic evaluation and accreditation of Study Centers and Courses (Galeoto et al., 2019). In 2016, the ANVUR reset the entire research design, including reference areas, the methodological approach and the means of detection, for both Transversal Competencies (TECO-T) and Disciplinary Competencies (TECO-D).

Transversal Competencies (TECO-T) are skills that college students can develop independent of the specific study route taken, and, therefore, they may be compared 
between different courses of study. Disciplinary Competencies (TECO-D) are closely related to capacity-specific training content in university studies, and, therefore, they can only be compared with study courses that are similar in nature.

Currently, the TECO project aims to construct indicators reflecting the skills of college students in the first and third years of a bachelor's degree program or a single cycle in Italian universities. The work aims to assess the knowledge acquired during the medical and clinical degree course consistent with the latest European ESG guidelines.

The objective of the study is to determine if the TECO-D is a useful tool for measuring the Disciplinary Competencies acquired by students over three years in the nursing bachelor's degree program at the 'Sapienza' University of Rome. Materials and Methods

\subsection{Population and procedures}

The sample was recruited between January and April 2018. To be included in the study, the participants had to be enrolled in the bachelor's degree course in nursing at the 'Sapienza' University of Rome. They were also required to be within the prescribed timeframe for the course of study that is, not progressing through the course at a slower or faster rate than the standard tree year timeframe.

Participation in the TECO project was voluntary for universities, courses and students, and, at the time of recruitment, the participants were informed about the modalities and objectives of the project.

The test was administered digitally in university computer rooms during 170-minute sessions (Freeman et al., 2010). The results of the tests were communicated individually to the participating students and did not affect the evaluation in progress or the final evaluation, while the aggregated data were transmitted to the coordinators of the study courses involved and to the university referents.

\subsection{Instrument}

The Transversal test (TECO-T) was divided into numeracy and literacy portions.

The first section, Literacy, consisted of 30 reading comprehension questions (compilation time, 35 minutes) divided into the following categories:

- A piece followed by ten closed-answer questions.

- A short passage from which 20 words were missing (Cloze test).

The second section, numeracy, consisted of 25 questions (compilation time, 45 minutes) asking participants to understand and solve logical-quantitative problems divided into the following categories:

- A short piece with graphs and tables, followed by five questions.

- An infographic followed by five questions.

- Five short questions of logical reasoning.

The disciplinary test (TECO-D) for the nursing bachelor's degree course used in this study was a tree file consisting of 70 closed questions with five alternative answers each. It was divided into eleven macro areas, as shown in Table 1. 
Table 1 Macro areas of TECO-D for nursing bachelor's degree

\begin{tabular}{lcc}
\hline Number macro areas & Learning & Number questions \\
\hline 1 & Transversal and vital criticality & 17 \\
2 & Cardio-respiratory & 11 \\
3 & Hematology & 4 \\
4 & Metabolic & 4 \\
5 & Gastro-intestinal & 4 \\
6 & Neurological & 4 \\
7 & Surgical 6 questions; & 6 \\
8 & Patient safety & 6 \\
9 & Hospital admission & 7 \\
10 & Organisation & 3 \\
11 & Ethical responsibility & 4 \\
\hline
\end{tabular}

\subsection{Data collection and data analyses}

For each year of study, data was collected for each of the main areas of the TECO-D, and, through SPSS-23 software, the data were registered in terms of the mean and standard deviation of the score distributions.

\section{Results}

The sample for the study was composed of 3109 students of the physiotherapy bachelor's degree course. Of these, 258 (7.6\%) were excluded because the students were out of the course timeframe; they had not completed their university exams within the set time period. Demographic characteristics of the population are reported in Table 2.

Table 2 Demographic characteristics of the 258 participants

\begin{tabular}{lc}
\hline & Sample $=3,109$ \\
\hline Age mean (SD) & $26.1(5.4)$ \\
Gender male n (\%) & $933(30)$ \\
\hline & Year of course $n(\%)$ \\
\hline First year & $1,084(34.9)$ \\
Second year & $869(28)$ \\
Third year & $902(29)$ \\
Fourth year & $254(8.1)$ \\
\hline
\end{tabular}

The distribution of the TECO-D scores shows an increasing average from 177,3 in the first year to 214.1 for graduating students (Figure 1). 
J. Sansoni et al.

Figure 1 The mean of the total scores for year of course (TECO-D) (see online version for colours)

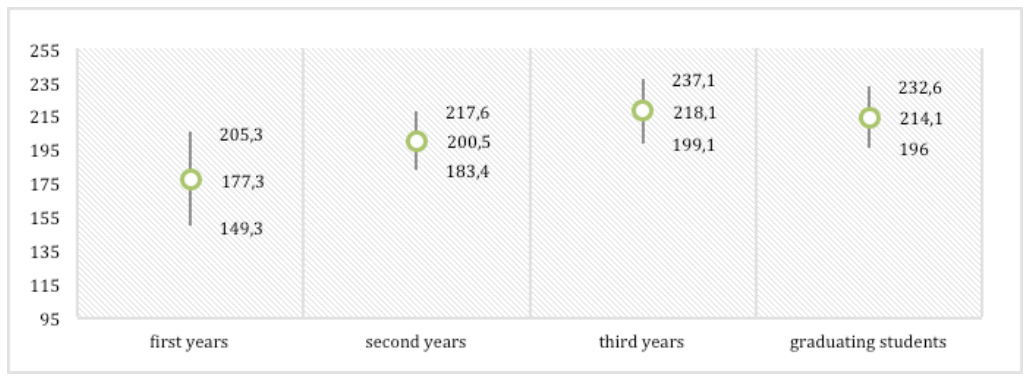

The distribution of the scores for the first, second, third and fourth macro area shows an increasing average from the first to third year of the course. The score of the macro area is unchanged between the third year and graduating students. The population data are shown in Figures 2-3.

Figure 2 The mean of the scores for year of course (TECO-D-macro area 1) (see online version for colours)

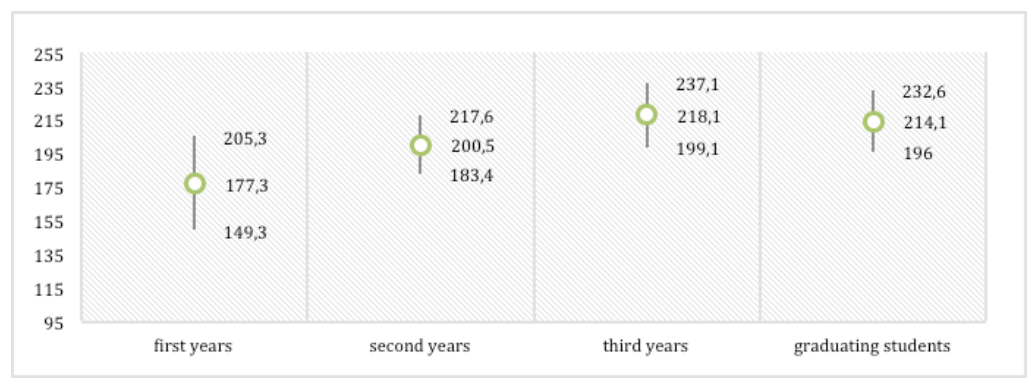

Figure 3 The mean of the scores for year of course (TECO-D-macro area 2) (see online version for colours)

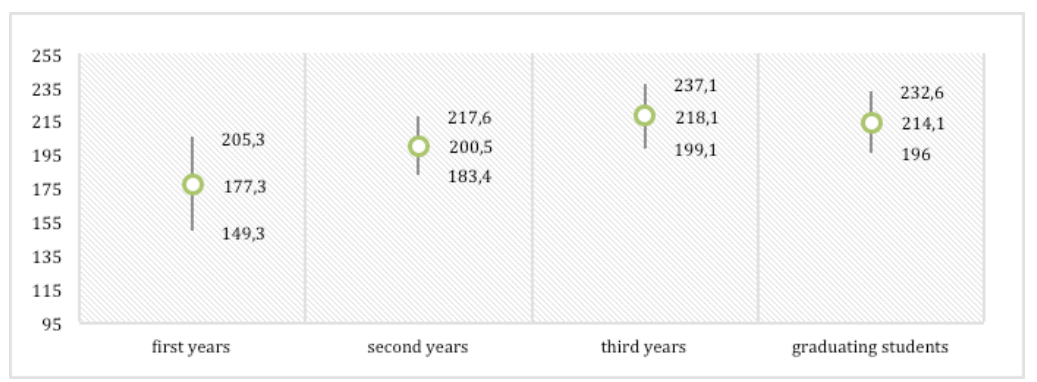


Figure 4 The mean of the scores for year of course (TECO-D-macro area 3) (see online version for colours)

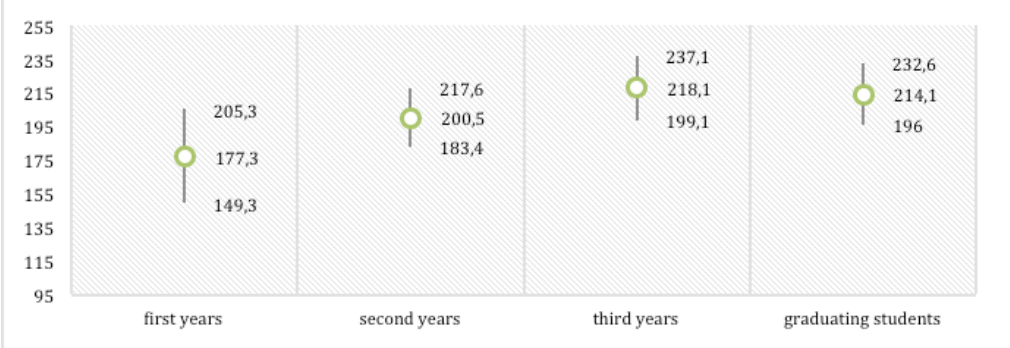

Figure 5 The mean of the scores for year of course (TECO-D-macro area 4) (see online version for colours)

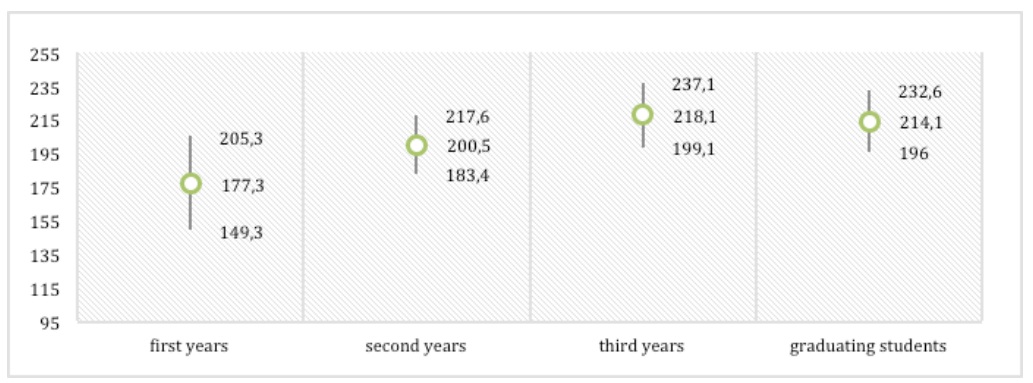

The distribution of the scores for the fifth macro area shows a constantly growing average from the first to third year of the course, but the score decreases in undergraduates students. The population data is shown in Figures 6.

Figure 6 The mean of the scores for year of course (TECO-D-macro area 5) (see online version for colours)

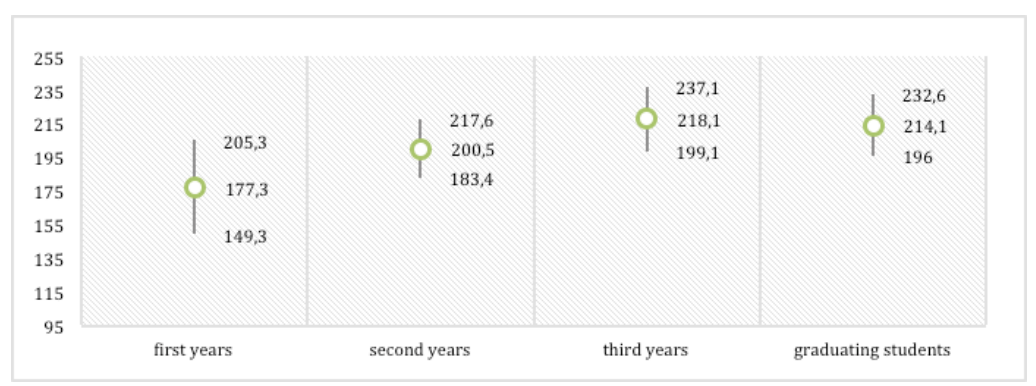

The distribution of the scores for the sixth and seventh macro area shows an increasing average from the first to third year of the course. The score of the macro area is 
unchanged between the third year and graduating students. The population data are shown in Figures 7-8.

Figure 7 The mean of the scores for year of course (TECO-D-macro area 6) (see online version for colours)

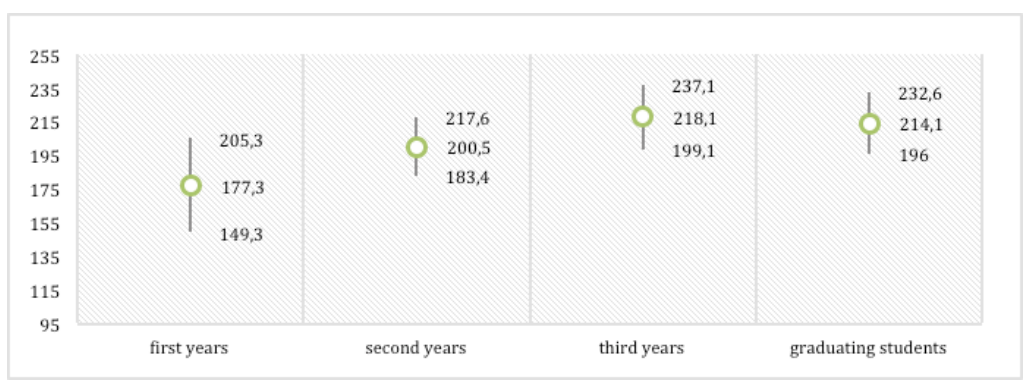

Figure 8 The mean of the scores for year of course (TECO-D-macro area 7) (see online version for colours)

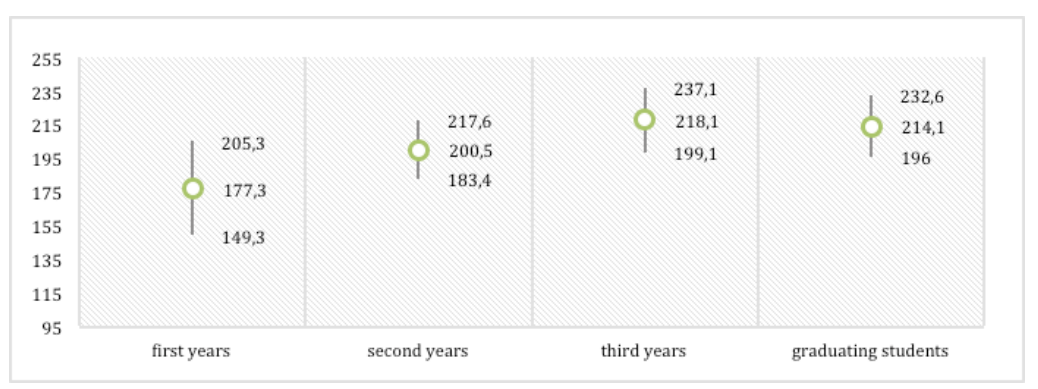

The distribution of the scores in the eighth macro area shows an exponential growth from the first to the second year, which remains stable in year three but increases again in graduating students. These population data are shown in Figure 9.

Figure 9 The mean of the scores for year of course (TECO-D-macro area 8) (see online version for colours)

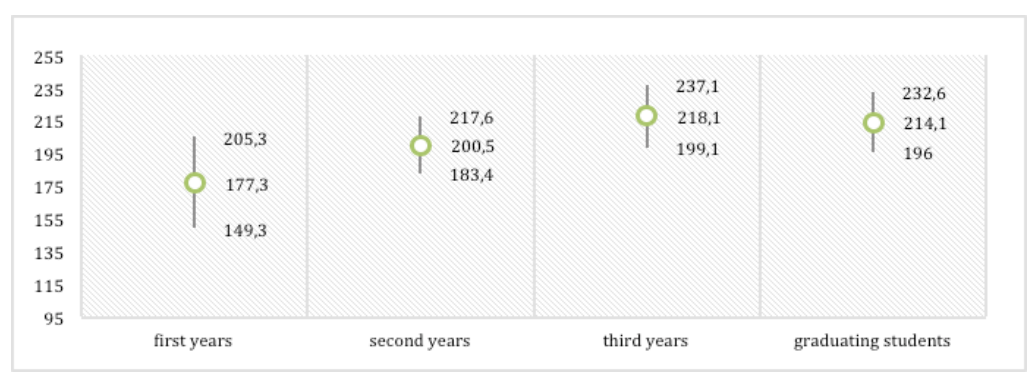


The distribution of the scores for the ninth, tenth and eleventh macro area shows an increasing average from the first to third year of the course. The score of the macro area is unchanged between the third year and graduating students. The population data are shown in Figures 10-12.

Figure 10 The mean of the scores for year of course (TECO-D-macro area 9) (see online version for colours)

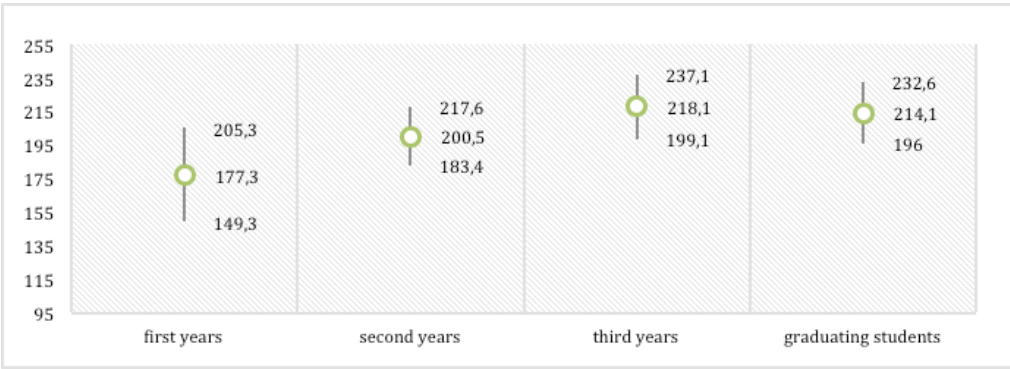

Figure 11 The mean of the scores for year of course (TECO-D-macro area 10) (see online version for colours)

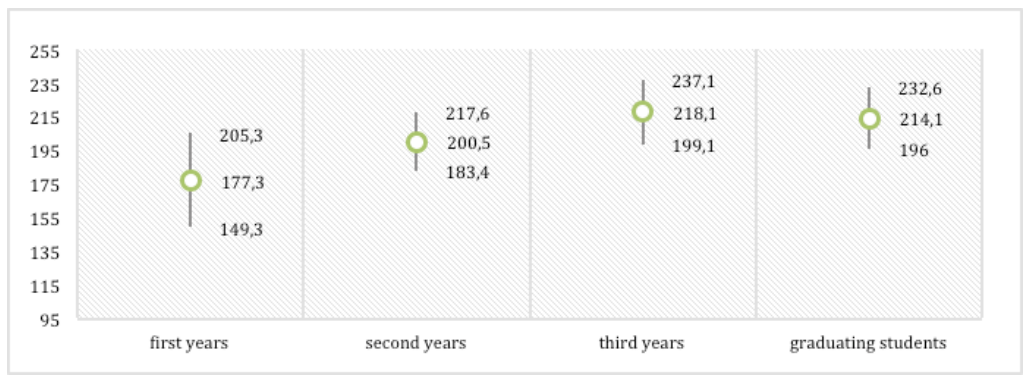

Figure 12 The mean of the scores for year of course (TECO-D-macro area 11) (see online version for colours)

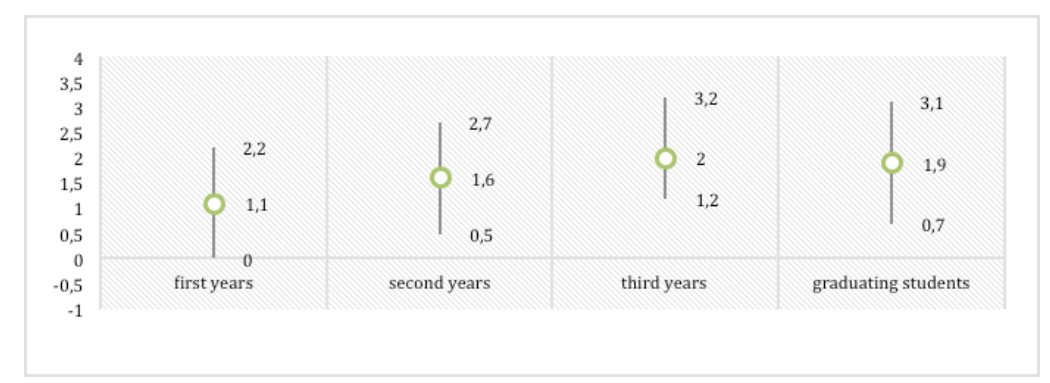




\section{Discussion}

The objective of this study was to evaluate the TECO-D as a measurement tool to assess the skills acquired, over three years, by students in the nursing bachelor's degree course at the 'Sapienza' University of Rome. This is an excellent opportunity for students to be exposed to experimental learning.

Progress testing is a form of assessment in which groups of learners of different seniority (i.e., different classes in a curriculum) are given the same written test. The test is comprehensive by sampling all relevant disciplines in a curriculum, usually determined by a fixed blueprint. Because of the need for wide sampling, questions are typically of the multiple-choice type. The test is repeated at regular intervals (Freeman et al., 2010).

The distribution of the scores for the TECO-D shows an increasing average from the first to third year of the course. The score of the TECO-D is unchanged between the third year and graduating students.

This data shows that the tool we use is able to assess the individual competencies acquired by the student for the three years of the course, but does not seem to be sensitive to the evaluation of the advanced competencies at the end of the course.

In 9 macro areas, out of the 11 present in the tool, an exponential increase was found between the first and third year of the course. The result is comparable to the total score obtained by the students. Data show that students do not get new skills in the last year of the course; this is given by the failure of questions that investigate the skills of the third year of nursing students.

The evaluation of the single macro areas showed statistically significant data reflecting increasing knowledge regarding the progression of the skills received during the university course. Because of this, we can say that the TECO-D is a great tool for determining student's knowledge in order to evaluate study programs.

This study was conducted by a research group composed by medical doctors and rehabilitation professionals from the 'Sapienza' University of Rome and from 'Rehabilitation and Outcome Measure Assessment' (ROMA) association. ROMA association in the last few years has dealt with several systematic reviews and the validation of many outcome measures in Italy (Culicchia et al., 2016; Castiglia et al., 2017; Marquez et al., 2018; Galeoto et al., 2017, 2018a, 2018b, 2018c; Murgia et al., 2018; Berardi et al., 2018; Tofani et al., 2018; Parente et al., 2017).

\section{Conclusions}

TECO is the first experience in Italy in the field of higher education and is rapidly gaining the interest of evaluators and researchers from other countries. Future studies will allow the test to contribute to improving the quality of the training process consistent with the latest European ESG guidelines, which promote student-centred teaching, accompanied by an analysis of learning outcomes. 


\section{References}

Berardi, A., De Santis, R., Tofani, M., Marquez, M.A., Santilli, V., Rushton, P.W. et al. (2018) 'The wheelchair use confidence scale: italian translation, adaptation, and validation of the short form', Disabil Rehabil Assist Technol., Vol. 13, No. 6, pp.575-580, DOI: 10.1080/ 17483107.2017.1357053.

Blake, J.M., Norman, G.R., Keane, D.R., Mueller, C.B., Cunnington, J. and Didyk, N. (1996) 'Introducing progress testing in McMaster University's problem-based medical curriculum: psychometric properties and effect on learning', Acad. Med., Vol. 71, No. 9, 1002-1007.

Castiglia, S.F., Galeoto, G., Lauta, A., Palumbo, A., Tirinelli, F., Viselli, F. et al. (2017) 'The culturally adapted Italian version of the Barthel Index (IcaBI): assessment of structural validity, inter-rater reliability and responsiveness to clinically relevant improvements in patients admitted to inpatient rehabilitation centers', Functional Neurology, Vol. 32, No. 4, p.221.

Coombes, L., Ricketts, C., Freeman, A. and Stratford, J. (2010) 'Beyond assessment: feedback for individuals and institutions based on the progress test', Med Teach., Vol. 32, No. 6, pp.486-490.

Crowe, A., Dirks, C. and Wenderoth, M.P. (2008) 'Biology in bloom: implementing Bloom's taxonomy to enhance student learning in biology', CBE Life Sci. Educ., Vol. 7, pp.368-381.

Culicchia, G., Nobilia, M., Asturi, M., Santilli, V., Paoloni, M., De Santis, R. et al. (2016) 'Cross-cultural adaptation and validation of the Jebsen-Taylor hand function test in an Italian population', Rehabilitation Research and Practice, http://dx.doi.org/10.1155/2016/8970917.

Freeman, A., van der Vleuten, C.P.M., Nouns, Z. and Ricketts, C. (2010) 'Progress testing internationally', Medical Teacher, Vol. 32, No. 6, pp.451-455.

Galeoto, G., Berardi, A., De Santis, R., Di Valentini, L., Beccasio, R., Marquez, M.A. et al. (2018a) 'Validation and cross-cultural adaptation of the Van Lieshout test in an Italian population with cervical spinal cord injury: a psychometric study', Spinal Cord Ser Cases, Vol. 4, p.49, DOI: $10.1038 / \mathrm{s} 41394-018-0083-6$.

Galeoto, G., Colalelli, F., Massai, P., Berardi, A., Tofani, M., Pierantozzi, M., Servadio, A., Fabbrini, A. and Fabbrini, G. (2018b) 'Quality of life in Parkinson's disease: Italian validation of the Parkinson's disease questionnaire (PDQ-39-IT)', Neurol Sci., November, Vol. 39, No. 11, pp.1903-1909, DOI: 10.1007/s10072-018-3524-x.

Galeoto, G., Sansoni, J., Scuccimarri, M., Bruni, V., De Santis, R., Colucci, M. et al. (2018c) 'A psychometric properties evaluation of the Italian version of the geriatric depression scale', Depress Res. Treat, DOI: 10.1155/2018/1797536.

Galeoto, G., Rumiati, R., Sabella, M. and Sansoni, J. (2019) 'The use of a dedicated platform to evaluate health-professions university courses', 8th International Conference Methodologies and Intelligent Systems for Technology Enhanced Learning, pp.275-284, Springer, Cha, DOI: $10.1007 / 978-3-319-98872-633$.

Galeoto, G., Sili, A., Tamburlani, M., Farina, M., Mannocci, A., Mollica, R. and Servadio, A. (2017) 'Construction and validation of a tool for the evaluation of environmental risks and limitations to the manual handling of loads: cross-sectional study', Clin. Ter., November-December, Vol. 168, No. 6, e349-e356, DOI: 10.7417/T.2017.2033.

European Standards and Guidelines for Quality Assurance (ESG) (2015) [online] http://attiministeriali.miur.it/anno-2016/dicembre/dm-12122016.aspx (access 18 December 2018).

Mangayarkarasi, V., Kalaiselvi, K., Kavitha, D., Chitraleka, V. and Balaji, R. (2019) 'Program-based teaching and learning to increase competency in undergraduate medical students using a model of the revised national tuberculosis control program', JMBE, Vol. 20, No. 1 .

Marquez, M.A., De Santis, R., Ammendola, V. Antonacci, M, Santilli, V., Berardi, A et al. (2018) 'Cross-cultural adaptation and validation of the 'spinal cord injury-falls concern scale'

Comment [W6]: Author: Please provide the issue number.

Comment [W7]: Author: Please provide the page numbers. 
in the Italian population', Spinal Cord., Vol. 56, No. 7, pp.712-718, DOI: 10.1038/ s41393-018-0070-6.

Momi, B. and Laxmi, P. (2014) 'Evaluation of different teaching methods used in physiology lectures', Indian J. Basic Appl. Med. Res., Vol. 4, No. 1, pp.271-276.

Murgia, M., Bernetti, A., Delicata, M., Massetti, C., Achilli, E.M., Mangone, M. et al. (2018) 'Inter-and intra-interviewer reliability of Italian version of pediatric evaluation of disability inventory', Ann Ig., Vol. 30, pp.153-161, DOI: 10.7416/ai.2018.2206.

Parente, M., Tofani, M., De Santis, R., Esposito, G., Santilli, V. and Galeoto, G. (2017) 'The role of the occupational therapist in disaster areas: systematic review', Occup Ther Int., DOI: $10.1155 / 2017 / 6474761$.

Schurwirth, L., Bosman, G., Henning, R., Rinkel, R. and Wenink, A. (2010) 'Collaboration on progress testing in medical schools in the Netherlands', Med Teach., Vol. 32, No. 6, pp.476-479.

Shandana, A.K., Mian, A. and Sadia, N. (2015) 'Trends in medical education from traditional to integrated system: valued by first year MBBS students at a private medical college of Peshawar', J. Med. Stud., Vol. 1, No. 1, pp.1-8.

Tofani, M., Candeloro, C., Sabbadini, M., Lucibello, L., Figura, M., Fabbrini, G. et al. (2018) 'The psychosocial impact of assistive device scale: Italian validation in a cohort of nonambulant people with neuromotor disorders', Assist Technol., pp.1-6, DOI: 10.1080/ 10400435.2018.1469553.

van der Vleuten, C.P.M., Verwijnen, G.M. and Wijnen, W.H.F.W. (1996) 'Fifteen years of experience with progress testing in a problem-based learning curriculum', Med Teach., Vol. 18, No. 2, pp.103-110. 